\title{
The Vitality of Interconnectedness: Vast's Service Delivery Programme, First Alone, Then Together
}

\author{
Mahshid Esfandiari and Frances MacQueen
}

\begin{abstract}
Workwith survivors of torture requires a delicate balance of therapeutic approaches. This article presents the work of the Vancouver Association for the Survivors of Torture (VAST) bydelving into some of VAST Therapeutic Principles of Care. It surveys the various therapeutic approaches embraced by VAST which help bridge the inside and outside world of survivors of torture. Among these approaches, bodywork plays a significant role in establishing this bridging. Most of all, this article emphasizes the need to respect the leads from the survivors themselves. Culturally appropriate and sensitive treatment approaches are central. All of these salient factors contribute to the holistic approach emphasized by VAST in order to join hands with survivors on their way to building a sense of interconnectedness and human vitality.
\end{abstract}

\section{Introduction}

\section{Résumé}

Le travail avec des rescapés de la torture requiert un équilibre délicat entre diverses approches thérapeutiques. Cet essai présente le travail de l'Association des survivants de la torture de Vancouver (VAST - Vancouver Association for the Survivors of Torture), en explorant quelques-uns des Principes thérapeutiques de soin de VAST. Cette étude examine les approches thérapeutiques variées utilisées par VAST quiaident des rescapés de la torture à établir un rapprochemententreleurs univers intérieur et extérieur. Parmi toutes ces approches, les soins apportés au corps jouent un rôle significatif dans l'élaboration de ce rapprochement. Mais cet essai fait surtout

Frances MacQueen, VAST, (Vancouver Association for the Survivors of Torture), Coordinator.

Mahshid Esfandiari, Ph.D., Psychologist, VAST, (Vancouver Association for the Survivors of Torture), Clinical Coordinator. ressortirle besoinderespecterles indications fournies par les rescapés euxmêmes. Des approches thérapeutiques culturellement appropriées et sensibles, sont primordiales. Chacun de ces facteurs saillants joue un rôle dans l'approche holistique mise en oeuvre par VAST afin de tendre la main aux survivants et deles soutenir dans leurs efforts pour élaborer un sens d'interconnexion et de vitalité humaine.

The Vancouver Association for Survivors of Torture(VAST), although a small NGO, plays a crucial role in serving the needs of refugees who have survived torture. In 1999, they saw over 300 people from over 50 countries as well as debriefing over 300 Kosovars. The staff comprises of a coordinator, a clinical coordinator who is a psychologist and a support staff. The clinical coordinator oversees the volunteer work of the team of psychologists and psychiatrists. Other important players in VAST are the team of six body care practitioners as well as the cultural interpreters who work closely with the clinical coordinator.

But, whatbrings refugee service providers to this kind of work- In this line of work, feeling that the endeavours make a difference is part of the driving force. In fact, making a difference is a sustaining value. Frances illustrates it:

There are two things in terms of sustaining me. One is I think it's a real honour to witness somebody's story. That's sustaining. And the other is the fact that one can make a real difference in someone's life. They're very small differences, but what an honour to be able to do that. And then other times, it's really big. I can honestly say that I've saved many people's lives by getting them to a safe haven or by finding someone who could do that in the homeland.... It's these kinds of victories in this office that we get. I mean, the beautiful serendipities that happen here from time to time and moment to moment. We probably have one at least every week.

The coordinator organizes VAST's services from the outside mainly because we need to have someone who is designated to be the outside contact as well as to oversee the services from within. In this capacity, the coordinator also provides practical support for people who have survived torture, but in truth, we all provide support for each other in many ways, in structured and unstructured ways. For the coordinator, the question is why do such work? The response is:

I think I happen to be good at it. If you ask me why am I good at it, I don't really know. It's very easy for me to make a connection with people and I feel very connected with people. I have a long history of human rights activity. I'velived in countries where human rights violations are a regular occurrence and part of the normality of life. I've lost friends to political violence, so it's part of my history.

Although the coordinator does not think of herself as a survivor of torture, she sometimes shares with refugees some of her experiences to let them know that they are not alone. "I think it's very reassuring for some people that it is not the end of the world, nor the end of the road. So I might choose to tell some people. With other people, it does not come up."

As clinical coordinator, Mahshid's role is diverse.

If there are people who are in immediate need, I will seethem. Then, I will continue with some of them for therapy. As well, I organize the therapists' team, interview the therapists and bring them to the team. I also do the referrals and arrange for the interpreters. I try to take care of the therapists' needs.

The clinical coordinator also organizes monthly meetings and invites speakers to meetings and organizes the body workers' team, since working to- 
gether is essential. Tocomplement psychological therapy, survivors of torture (participant is the term VAST uses) are referred to the body workers. Thus, "we work alongside with them: I do the therapy and they do the body work. As well, we spend time and talk about the changes in the person."

\section{VAST's Clinical Philosophy:} Therapeutic Principles of Care

For those that may have a calling to this line of work, the question may emerge whether a particular clinical philosophy is necessary. However, there is not one that can be easily categorized. We assume that people are made of their experiences. This means that what someone may be dealing with may not be just about the torture itself. It could be related to their childhood experiences or their social experiences etc. For example, if they immigrated or are in a refugee situation, the difficulties may be connected, but it is not specifically about the tortureexperience. It doesnotmatter to us, what it is connected to, or what the problem is. The main objective is to allow the persons tobe. We bring them to where they can pay attention to what their needs are at this time and how we can cooperate to help each other to meet their needs, whatever it relates to. If we take care of this need, which in the present session, we may gradually take care of the layers. Along the way, we may end up facing the torture and we realize, "Oh, there it is!" That's why this person is having a hard time in this situation, of having experienced it previously elsewhere, either in childhood or in a trauma experience.

Through the process of building a relationship, we do not put something aside and say, "Okay, this has nothing to do with me, and I am not going to talk with you about this, let's talk about the torture. No, that's not the way we work." This is about life, about learning how to get back again to who they were before the torture. Survivors of torture become frozen in time by the torture. Therefore, we work to maneuver around those experiences and untangle them. It is about coming to recognize that the torture was a small portion of their lives. In all of this, it is important to reawaken memories of good experiences, which are forgotten because of the torture. Thus, this is about how to be able to get back to normal life again!

VAST's service delivery programme is both constant in its aim and flexible enough to adapt to changing circumstances. Every aspect relates directly to the same concepts. Frances explains: "I don't get to determine what happens, the person determines that. That's very important." When a person comes to our center, the process starts off with Frances, who does the initial intake. Over time, the process for the intake has changed. As Frances describesit, "there is no one set procedure." This has to do with a number of factors guided by years of experience in doing this work and by what is told to us. Flexibility, careful listening and looking, clarity of purpose and loads of discussion, all impact the nature of the intake. This learning process can be both invigorating and frustrating. According to Mahshid, "There isnoblueprint we can look to. It's important to us all that there are some consistencies, but the only hard and fast rule is the principle of care" (see box below).

\section{The "Usuals"}

Since there is no strict set of procedures, we prefer to call them 'the usuals'. The intake takes about an hour. This is when Frances asks questions about the person's physical health, although a physician from Vancouver Hospital regularly sees people at VAST. She explains how VAST works, who the funders are and what is the range of services offered. A diverse number of options are available, from practical support such as bus tickets or a snack or bodywork such as massage therapy or psychological counselling and psychiatric services. An explanation of VAST's protocol around confidentiality and safety follows. Usually, by the end of an hour, the person has determined which services, if any, she or he wants. Generally, the follow-up meeting with Frances is also arranged at this time and such appointments are made before the person leaves.
VAST TherapeuticPrinciples ofCare 1. Be trustworthy, recognize it takes time robulid trust:

2 Stress confidentiality.

3. Avoid assessment and treatment approaches which may re-victimize survivors, such as intrusive probing into past trauma.

4. Ensure that the program participant feels a sense of control over the therapy process.

5. Be sensitive and responsive to the varrety and holistic (physical, psychological, spiritual and social) needs of survivo:s oftorture:

6. Strive to understand the individual in thecontext of their family and provide care to build or restore healthy family relations.

7. Bealert to "triggers" in the centre's environment, like uniforms or lengthy waiting periods.

8. Seek knowledge about the culture of individual participant and the human rights conditions and history in their country of origin.

9. Use culturally sensitive and appropriate trea tmentapproaches.

10. Beflexibleand willing to be available for survivors.

11. Focus on the streng this of the programme participant, not solely on their problems.

12. Recognize that interpreters actas cultural interpreters and are a valuable resource as part of the VAST team.

13. Be conscious and responsive to one's own reactions during care, such as counter-transference and secondary traumatization.

14. Maintain anopen commitment to human rights.

"We've evolved this process to take into account that we can and must be able to let go of 'procedure,' should the situation call for it," says Frances. "We've learned that the most effective way is people-before-administration." So we may or may not ever learn the story of the person's torture, their real name, country of origin. Usually we do, butnot always. And that has to be accepted. Otherwise we are holding on to our agenda, instead of paying attention to their needs. Since the experience of torture is different for every person, thera- 
pists need to work with the information each person provides. During this process, the therapist needs to stay with the person in the present. Because the torture experience is so injurious, the person may avoid talking about it. The therapist may then focus on how the person is doing now, what he or she is feeling, with whom they are maintaining contact on a daily basis. However, it is in these interactions that unfolding occurs. Gradually the person unfolds glimpses that allow the therapist and the person to see the root of what is creating the situation. It is then that the survivor begins to recognize his or her needs.

As a therapist, one does not want to go to the experience of torture, because this is very uncomfortable. Sometimes the therapist does not get the whole story, but through this interaction, a participant begins to rediscover his or her needs. This is critical because the person was denied his or her needs. In fact, the person has forgotten what his or her needs are. Thus, in the therapeutic context, we teach survivors that their needs are important. The participant leads you to where you are at that particular moment. It is then that the therapistmay respond with, "Let's talkabout this." A therapist cannot expect to get the whole story at once, but must be extremely patient and allow the small glimpses to emerge gradually.

None of our case histories is typical. However, following VAST principles is critical, regardless of the case. The following two stories may illustrate how the principles work in practice. The true identity is concealed in order to protect the confidentiality of the persons. Any parallel with a real person is merely coincidental.

\section{Case History 1}

A Canadian Immigration officer contacted us to discuss resources for a twenty eight year old woman, " $B$," who had arrived very recently and had a history of trauma in her country of origin. VAST was hosting a barbecue in a local park the nextday and we told the officer that she would be very welcome to at- tend. At the barbecue " $B$ " played football, soccer, and ate and drank with other program participants. Conversation was very limited, but everyone made an effort to engage her in conversation. " $B$ " spoke German very well, which was the only common language and Frances strove to convey the mandates and workings of VAST and she was invited to phone us.

After two weeks, she phoned for an intake. Since we had some knowledge of her ethnic and political background, an interpreter was arranged with similar history. During the intake conducted in her first language, she gave a false name and said that her country of origin was Germany. She presented predominant avoidance symptoms: emotional constriction, low affect and social isolation. Therapy was set-up using a female Swiss German interpreter on a weekly basis. Initial subjects for discussion were her present daily contacts and activities at her English language classes. The therapist also focused on her body posture, drawing attention to how she carried her body and how she was breathing. A concern of the staff was the apparent loss of weight. When asked about it, she answered that she ate merely for energy to carry her body around, that she experienced no enjoyment from food and had no appetite.

In a later discussion she talked about herbelief that most people werebad and that there were only a very few people who were good in this world. She had not at this point discussed any of her traumatic experiences and conversation remained with present day events as well as her opinions. She was given an assignment to draw any of the good people that she had known with suggestions that she could put them in a boat, likeNoah's Ark, so that they could be saved from the flood. The next session she brought in a drawing with her family members in the Ark. Her family members were all dead; her father of sickness, her siblings were killed in the war and her mother died after her health was affected by the death of "B's" siblings. This led to a discussion on the beginning of her past, her childhood with her grandmother whom she loved very much and with whom she spent most of her childhood. Discussion on hergrandmother invoked happymemories and led to a conversation about her grandmother's cooking which she remembered with gusto. The therapist gave her the task of trying to remember the recipes and to re-create those foods as a comfort. She began to gain weight. After four months of therapy, she introduced herself to another program participant by her own name and country of origin.

All of the therapy was directed by "B." The therapist did not lead, "B" did. When she was numb, she was allowed to be, the therapist merely pointed out her observations with unconditional acceptance. She was not pushed to recall nor recollect and she became able to express anger and sadness. When these emotions returned, they were acknowledged. A turning point in her therapy came after about three months. She began to realize that most of her life had been positive (more good than bad had occurred in her life). Her energy returned and she began to be able to focus on her studies. Meanwhile, she came to the realization that she now had the freedom to choose a new course for her life. She chose not to return to nursing. Instead, she is continuing to explore the world that is hers, moving fast toward recovery. Comfortable in her homeculture as well as the Canadian mainstream culture, she is now socializing well. The exploration and discovery of other parts and qualities in herself continues while she maintains contact with and participates in VAST's social activities.

\section{Case History 2}

"P," a male in his mid-thirties brought his sister to VAST for advice to assist her with a failed refugee claim. He came through a recommendation by another political activist, "M." Later he revealed that he had been in prison with " $M$ " for many years. VAST services were explained to him while his sister was assisted. " $P$ " began to bring in other people who needed immigration assistance and we advised how and when we could, or made appropriate referrals. 
We joked with him and discussed the culture, politics and mutual stories or news.

After several months, he revealed that he believed that he would benefit from therapybut washesitant to receive it, especially from someone of his own culture. Thus, he was given a choice. We explained to him that should any therapist not suit or help him, he could try others, that "therapy was a bit like marriage. Therapists worked in different ways and one had to find the right person, a person with whom he feltcomfortable." All programme participants are told this. He elected to work with his original therapist, even though therapy sessions were initially hesitant and testing. Added to this dynamic was another, the influence of a political ally from another party who was receiving therapy at VAST. The ally persisted in trying to convince "P" that he should change to a Canadian-born therapist who was deeply committed to social justice.

Focus began on anger management, with a discussion on family relationships and the possible effects of being an inattentive parent. " $\mathrm{P}$ " was isolated into a small sub-culture from his country since he was still involved in political struggle and party activities. This was understandable since his identity was formed by his engagement as a radical activist for the poor at the age of thirteen. His parents were poor. Gradually, as a trusting relationship was built, he began to reveal glimpses of his experiences in prison and of the torture that he endured. The therapist responded to these glimpses by listening and moving away from the story without asking him to elaborate, referring himinstead to pay attention to his feelings and body reactions whilst he was speaking of the trauma. The therapist conveyed to him that her interest was in him as a person and on how his experiences were affecting him now. He then discovered for himself that bodies and feelings are interconnected. At this point he was also referred to a body care practitioner, a ReikiMaster with knowledge of Neurological Organizational Techniques. The body care practitioner worked in conjunction with the psychotherapist. He began to move to recovery very quickly. He and his child began to take classical music lessons arranged through VAST.

As he developed a stronger sense of himself and his internal strength, his marital relationship underwent a crisis. His trauma responses then became retriggered, but he recovered his emotional well being very quickly. This fast recovery was a surprising discovery for him, adding to his sense of self. $\mathrm{He}$ maintained therapy, attending approximately every two weeks whilsthe struggled with the fundamental issues precipitated by his wife's desire to leave the marriage. They live separately for now but maintain some continuing intimacy, always at the wife's behest or request. $\mathrm{He}$ is continuing to learn and is now self-processing his emotions. The therapy has helped him as he is now able to identify his issues and process them. Meanwhile, hechecks in approximately once every two months.

\section{Implications for Therapeutic} Practice

The "VAST Therapeutic Principles of Care" were taken from some research findings on survivors of torture on what may induce feelings of terror (Horowitz 1993, Martin-Baró 1994). A brief discussion follows to elaborate on a few of these principles. The discussion will be based on our own experiences as well as research findings. To open the door for programme participants toengage, two principles are essential to begin the process, safety and confidentiality, both of which go hand in hand. The major focus of intake is explaining to potential participants their rights and responsibilities as well as our rights and responsibilities.

Horowitz (1993) identifies several stages in the treatment of PTSD. In the first stage, it is essential to establish safety and to build trust. By trust, we say, "you can trust some people in some areas of your life. It's okay not to trust, and people are not expected to trust in all areas of their life." The most important thing is that the program participant trust his or her own feelings and instincts. This way, the program participant knows what is good for him or her at all times. He or she should listen to the inner voice and check out any personal hesitations.

When peoplefirst come to VAST, they have been hurt. An official has attempted consciously to destroy them and their ideals, perhaps has destroyed their family members or colleagues. To be more precise, another human being has acted previously in an unbelievable and unconscionable way, therefore anything becomes possible then. Consequently hypervigilance symptoms are predominant (common physical symptoms are flight, fight and freeze) and there needs to be constant reassurance to prevent triggering these responses. At the VAST office, we have signs that ask people if they experience anything which makes them feel unsafe, to please try to tell someone, any one of us, so that we can address this. In one particular case, a Nigerian saw a coat hanger which had been covered by crochet in green and white weave. He believed this had been placed there by the Nigerian Government (The flag is green and white). We immediately removed the coat hanger and promised him that he would not see it again in the office.

Among VAST Principles of Care, one recommends to "Be alert to triggers in the centre's environment, like uniforms or lengthy waiting periods." Triggers can be any thing and cannot be avoided, but we can take care of what we know about. We must, as professionals, respectboundaries, be non-intrusive and allow the program participant space.

Torture is used by repressive regimes and groups to systematically destroy an individual's personality and a society's sense of security. It plants the seeds of dismay and mistrust within a community and if given time, grows to become [an] immutable and ominous reminder of the terror that is so close at hand. Its effects are longlasting and widespread over all realms of the survivor's life; to all those who come into contact with him or her and to the entire community. This devastation is what has become so appealing to the torturer, 
and thus torture is often used as the ultimate and most powerful means to crush the adversary and the society from which they stem. (VAST 1995, p.2)

Another point to the trust and safety issue is that most of our program participants are or were political activists. Consequently, their governments may still be interested in silencing them since there are people in our midst who do report back. One of our Iranian participants was in a demonstration and within a week the government was showing a photograph of his participation to family members back home. There are valid concerns regarding spies and there are many examples of political insecurity. Most of our Program participants are very concerned about the safety of their family members and colleagues back home. This is a valid concern and one that mustbe taken seriously.

\section{The Family Context}

Social isolation generally is one of the results of the official and intentional infliction of pain and suffering (See Martin-Baró 1994). As a result, family relationships become threatened. It may be that the person's experience was so horrific that she or he cannot share the experience with his or her partner, or that if shared, the partner is unable to fully integrate this knowledge forhim or herself. Therefore, intimacy is broken as the survivor and his or her partner are unable to reach the intimacy that is needed in a healthy family context.

We are currently working with a couple who are both traumatized and unable to fully share their feelings and experiences with each other. Both are demanding acknowledgement and caring from the other. At this time, however, neither can summon up the resources needed to assist the other, since each one is totally occupied and absorbed with his and her own inner pain. Consequently, each one is frustrated with the other and upset with the demands placed upon him and her by the other. We are working individually with separate counsellors. In addition to the individual therapy, we are providing them 'couple counselling' in order to help them hear and to know themselves as well as each other.

In other examples, some parents have come to us because they are concerned about the behaviour of their children. In most cases, the problems experienced havebeen managed by working primarily with the parents. Healthy social interaction begins at home and works outward. In all of our work, our focus is to identify, acknowledge and normalize reactions to trauma. To do this, we encourage people to pay attention to their thoughts and feelings in the 'here-andnow.'

\section{Knowledge of Culture}

It is important to understand the political, religious and cultural context of any individual. However, the most important factor is then to suspend judgement and make no pre-conceived assumptions, because each person is a culture unto him or herself. VAST therapists allow the individual to teach and to inform us about his or her world scheme, according to what feels right at the time. We are also supportive about doing this at each individual's pace and wishes. Authentic interest expressed by the counsellor about the programme participant's world view and background culture are also a useful bridging to discuss values, ideas and to gain insight about inner workings.

\section{Culturally Sensitive Treatment Approaches}

Most newcomers are unfamiliar with our culture of counselling. To be effective, we believe it is important to allow the person to take the lead, to determine for him or herself "how," "when" and "what" they need to receive to move towards recovery. Thus, we modify our treatment approaches to accommodate the person's own pace and culture. We ask, "what would this person do?" Or "what would behelpful if he or she were in the country of origin?" An approach that has proven effective to VAST practitioners is bodywork.

\section{The Bodywork Team: Healing from Inside and Outside}

Torture is generally committed on the body to impact the soul or psyche. Thus body and mind both need attention. Working with survivors of torture is whole person work. Survivors are extremely vulnerable, sad and consumed with memories of being tortured. The memories are especially felt in the particular parts of the body that were injured. Furthermore, because of the trauma, survivors are not able to connect with the emotions associated with the trauma. Instead, in many cases, they endure body sensations. Therefore, bodywork is essential to give attention to the body while at the same time attending to emotions. In order to accomplish this, the survivor works with both the therapist and the bodyworker. It is a process of working both inside and outside. Each practitioner, though, has a different section to work on but provides feedback to the survivor as well as to the other practitioners. Thus, a therapeutic triangle is established. Amazingly "what you notice in therapy, the bodyworker experiences also, the same feelings."

Our body care practitioner team is being developed. It currently consists of six professionals from a variety of differing theoretical backgrounds. The team is represented by: 1) a Reiki Master with Neurological Organizational Technique(NOT) and Touch for Health theoretical knowledge; 2) a Rosen Method specialist; 3) an Alexander Technique specialist; 4) a specialist in Breema and Shiatsu;5) a massage therapist; and 6) a physiotherapist. Consequently, the bodywork team affords a variety of healing approaches, some involve touch while others focus on transmitting energy without touching the body. Reiki and Alexander, for example, work through energy transmission by placing the hands above the body or specifically above the injured part of the body. Among those that interveneby touching thebody are Breema, Rosen method, and Shiatsu. Kurdish people have made a contribution with the Breema method, which can be described as a combina- 
tion of massage and chiropractic techniques. Shiatsu works by massaging certain points in the nervous system.

Thus, touch can be above the body fromenergy sources, lightor deep tissue work. Again, VAST is careful to listen to the survivors' voices in their preferences as we make every effort to match needs to resources. Above all, we stress the need for the survivors to control what is happening to them, which is unlike their torture experiences. Now they have control of the processes that affect them. This is especially important since any bodywork may trigger traumatic memories.

\section{Conclusion}

Working with survivors of torture requires special skills and sensitivities from practitioners. Equally important is to offer a variety of therapeutic ap- proaches and modalities that are culturally appropriate and respectful of the programme participants. Above all, a holistic approach is necessary to connect with the person at various levels. Among the therapeutic approaches, we consider bodywork complementary to more mainstream psychological ones. In order to serve survivors from diverse cultural backgrounds, we attend carefully to the selection of cultural interpreters. Regardless of the approach, the survivor must provide the lead in the therapeutic process. If the survivor chooses in an instance not to receive therapy but to just share a cup of coffee or tea with other survivors or with the coordinator, this is accepted and respected. "If survivors just want to socialize, meet others from other cultures, or meditate at the center ... or talk with one of us or a staff person, we respect the boundaries set by the survivors," asserts Esfandiari. At VAST, the therapeutic principles of care provide guidelines to practitioners but most important, is letting the survivor lead the process supported in a safe and trustworthy setting.

\section{References}

Horowitz, Mardi J. 1993. Stress Response Syndrome: A Review of Posttraumatic and Adjustment Disorders." In John P. Wilson and Beverley Raphael (Eds.), International Handbook on Traumatic Stress Syndrome, New Yorkand London: Plenum Press, pp. 49-60.

Martin-Baro, Ignacio. 1994. Writings for Liberation Psychology. Cambridge, MA: Harvard UniversityPress.

VAST. 1995. VAST Basic Documentation, Vancouver, B.C., Unpublished. $\square$

\section{Callor Topes

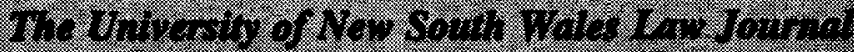

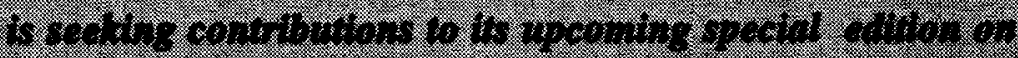 \\ RRTUCES AWD TIE WIT}

TheUNSWL Law Joumal is one of Australia's leading academic publications. The Jeumalis renowned forpublishing artickes which arerelevantuot only to acadenics, but to legaland business professionalisaswell.

Each year, the Ioumal produces a thernaticedition, which in 2000 will bedevoted to perspectives

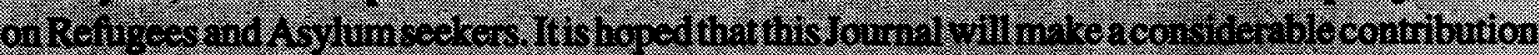

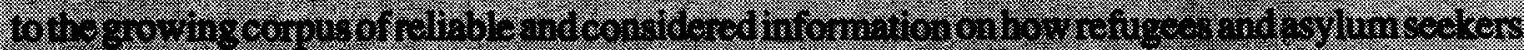

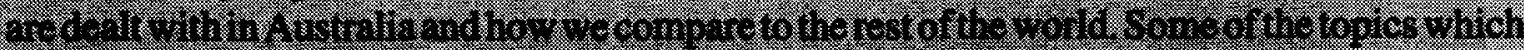
the Younlathopea to coveribclinde:

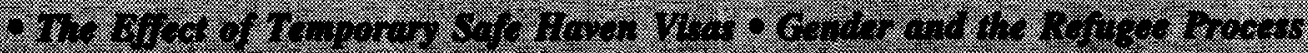

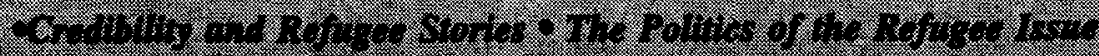

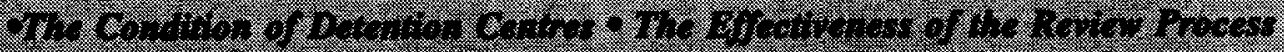

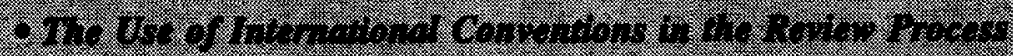

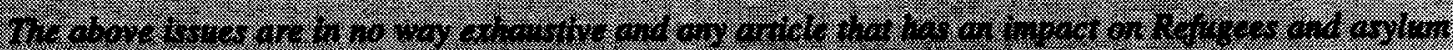

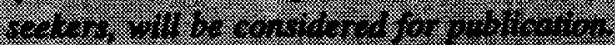

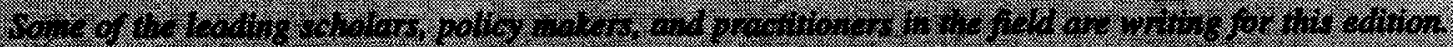

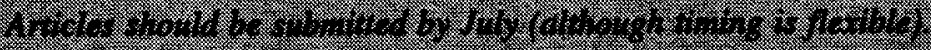

837. or by esmont law 